\title{
Giant Pituitary Adenoma Presenting with Foster-Kennedy Syndrome in a 21-Year Old Ethiopian Patient: A Rarely Reported Phenomenon: A Case Report
}

\author{
Biniyam Ayele $^{1^{*}}$, Abenet Mengesha ${ }^{1}$, Abdi Wotiye ${ }^{2}$, Yodit Alemayehu ${ }^{1}$
}

\footnotetext{
OPEN ACCESS

Citation: Biniyam Ayele, Abenet Mengesha, Abdi Wotiye, Yodit Alemayehu. Giant Pituitary Adenoma Presenting with Foster-Kennedy Syndrome in a 21-Year Old Ethiopian Patient: A Rarely Reported Phenomenon: A Case Report. Ethiop J Health Sci. 2020; 30(2): 311 . doi:http: //dx.doi.org/10.4314/ejhs.v30 i2.19

Received: November 27, 2019

Accepted: December 26, 2019

Published: March 1, 2020

Copyright: (C2020 Biniyam Ayele, et al. This is an open access article distributed under the terms of the Creative Commons Attribution License, which permits unrestricted use, distribution, and reproduction in any medium, provided the original author and source are credited. Funding: Nil

Competing Interests: The authors declare that this manuscript was approved by all authors in its form and that no competing interest exists.

Affiliation and Correspondence:

${ }^{1}$ Department of Neurology College of Health Sciences Addis Ababa University ${ }^{2}$ Department of Internal Medicine College of Medicine and Health Sciences Hawassa University

*Email: biniyam.a7@gmail.com
}

\section{ABSTRACT}

BACKGROUND: Disorders of the pituitary gland and the sellar region present a wide spectrum of clinical problems. A variety of lesions in this area tend to present with similar problems; namely, headache, hormonal disorders, and loss of vision. Benign adenomas of the pituitary gland are by far the most common disorders of sellar region. Rarely, patients with pituitary adenoma may present with blindness in one eye and visual field cut (temporal hemianopia) in the contralateral eye. This rare clinical entity is called Foster-Kennedy Syndrome (FKS).

CASE PRESENTATION: We present a 21-year-old male patient, presented with progressive visual disturbance of the left eye, associated with global headache. The headache was refractory to over-counter medications. In addition, he had history of sleep disturbance and loss of appetite. Neurological examination was pertinent for left side visual loss with optic atrophy and right eye temporal visual field cut with disc edema. Brain MRI showed $4 \mathrm{~cm}$ $X 3.5 \mathrm{~cm}$ sized lobulated intra and supra sellar mass with heterogeneous contrast enhancement and minimal surrounding edema. Serum prolactin level was 6,705 $\mathrm{ng} / \mathrm{mL}$. Otherwise, the other pituitary hormones were in normal range.

CONCLUSION: This case highlighted that pituitary adenoma may present with the full picture of Foster Kennedy syndrome. Therefore, we recommend considering pituitary adenoma as a possible differential diagnosis of intracranial lesions presenting as Foster Kennedy syndrome, as early detection and management could potentially salvage patients' vision and quality of life.

KEYWORDS: Foster Kennedy syndrome, Giant pituitary adenoma, Prolactinoma, Sellar mass

\section{INTRODUCTION}

Pituitary adenomas are in fact the second most common primary brain tumour. Depending on the specific tumour type, they range in incidence from 7 to 92 cases per 100,000 people per year, and in prevalence to approximately 1020 per 100,000 (1). In considering pituitary adenomas, the major distinction is between hyperfunctioning tumours presenting with typical hormonal syndromes, and clinically non-functioning tumours which usually 
present as relatively silent masses, causing headache, hypopituitarism, and compression of the optic chiasm, often producing the classical Bitemporal hemianopia. They are classified by functional subtype, size, and invasiveness (2).

Over half of all adenomas are secretory; these include, prolactin $(65 \%)$, growth hormone $(50 \%)$, adrenocorticotropin (10\%), thyrotropin $(6 \%)$, and mixed (1\%) (3). Pituitary adenomas sized more than $1 \mathrm{~cm}$ is called macro adenoma. Optic chiasm is one of the most common structures to be compressed by a macro adenoma. Occasionally, giant adenomas may result in increased intracranial pressure and mass effect on parasellar structures such as, cavernous sinuses. Rarely, giant adenomas may result in hydrocephalus and seizure by compressing the midbrain and adjacent temporal, respectively (2).

Foster-Kennedy Syndrome (FKS) is a relatively rare clinical entity, first described by Kennedy F. et al (5). FKS is defined by presences of ipsilateral optic atrophy and contralateral papilledema, and occasionally anosmia. FKS is said to be due to an intracranial lesion causing mass effect on ipsilateral optic nerve only to cause optic atrophy. In addition, the intracranial mass also causes increased intracranial pressure resulting in contralateral papilledema. FKS is often associated with orbitofrontal tumour, abscess of the frontal lobe, and meningioma involving olfactory groove. To the authors' knowledge, this is the first case reported from Ethiopia regarding giant pituitary adenomas presenting with FosterKennedy syndrome.

\section{CASE PRESENTATION}

We present a 21-year-old right-handed, male patient, who was apparently healthy 5 years back when he started to experience hemi-cranial throbbing type of headache involving temporal side of head and tends to alternate between right and left side. The headache was persistent throughout the day but got worse in the morning with no relieving or aggravating factor and also associated with sleep disturbance and loss of appetite. The headache was not preceded by premonitory symptoms. At local hospital, migraine headache was diagnosed and he was treated with multiple
NSAIDs medication. However, no clinical improvement was obtained. One year back, he started to experience blurring of vision on the left eye, and he failed to differentiate people and was unable to read with his left eye. The blurring of vision was progressive in type, which made it difficult for him to accomplish his college study. He feels clumsy and often shoulder bump to doors while walking.

Neurologic examination was pertinent for left side optic atrophy and right eye grade IV papilledema. On the left eye, he only had minimal light perception. On the right eye, he was able to count finger from six meter, but visual field examination showed temporal visual field cut (temporal hemianopia) (Figures 2). Otherwise, other system examinations were unremarkable. Brain MRI revealed a $4 \mathrm{~cm}$ X $3.5 \mathrm{~cm}$ sized lobulated intra and supra sellar mass with heterogeneous contrast enhancement and minimal surrounding edema. Clinical and radiological evidences were suggestive of pituitary macro adenoma (Figures 1A and 1B). Pituitary hormonal profile showed normal study of thyroid hormones, morning cortisol, growth hormone and IGF-1. However, serum prolactin level was extremely high $6,705 \mathrm{ng} / \mathrm{mL}$ (Table 1). The underlying cause of FKS in our patient was not only mass effect from the pituitary adenoma, but also from chronic increased intracranial pressure which causes papilledema of the contralateral optic disc. Thus, combined effect of chronic intracranial hypertension and mass effect from the adenoma resulted in atrophy of ipsilateral optic disc and edema of contralateral optic disc.

Transphenoidal biopsy is helpful in confirming histological sub-type of pituitary adenoma. However, this procedure is not commonly practiced in Ethiopia. Because of these, a diagnosis of prolactinoma was made based on extremely high serum prolactin level, $6705 \mathrm{ng} / \mathrm{ml}$ $(1.8-20 \mathrm{ng} / \mathrm{mL})$. Considering high responsiveness of prolactinoma to dopamine agonist medication, such as oral Bromocriptine $2.5 \mathrm{mg}$ daily was started. On follow up patient' clinical symptoms showed significant improvement, so does the serum prolactin, which dropped to $104 \mathrm{ng} / \mathrm{ml}$. 


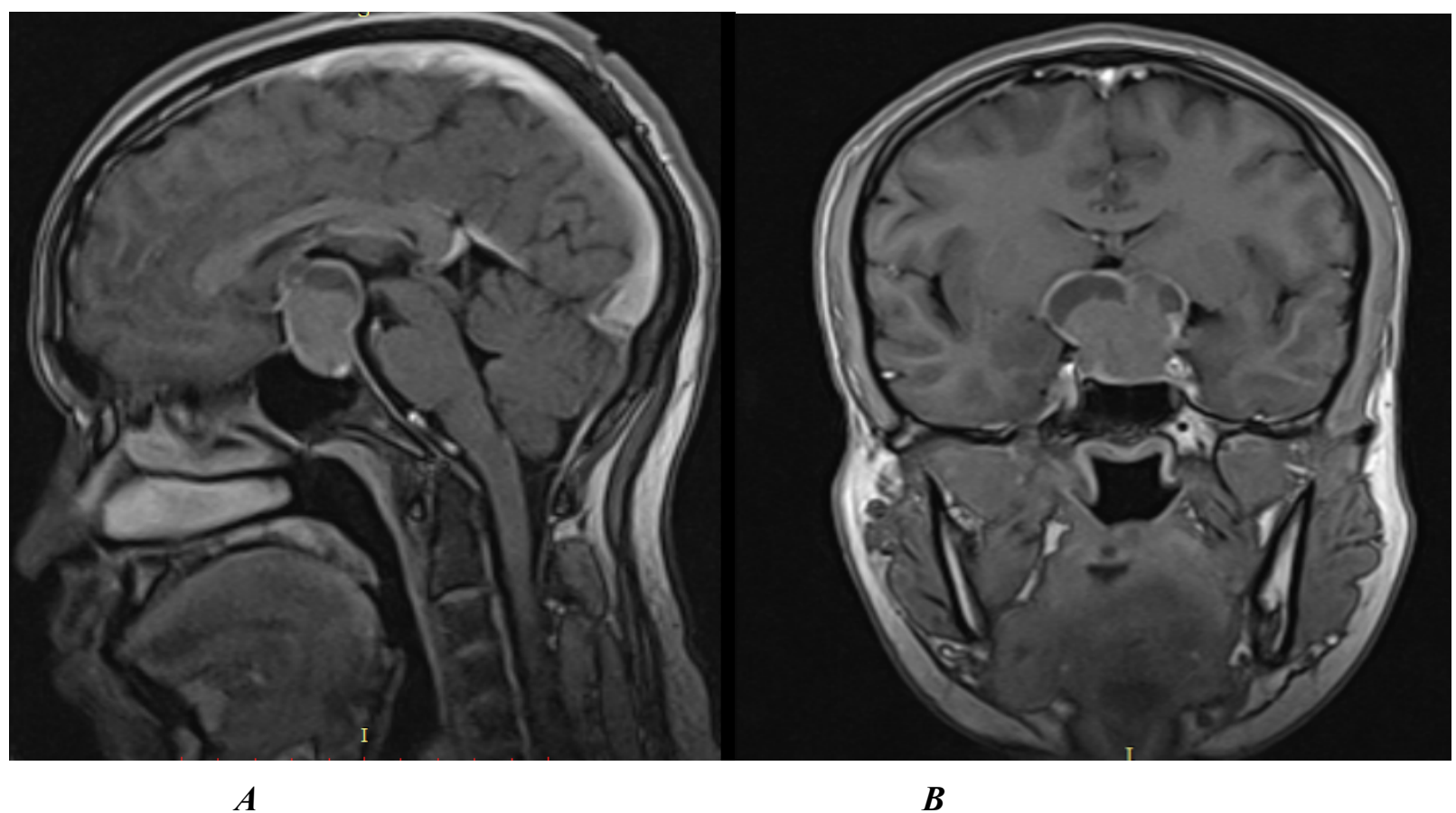

Figure 1: Sagittal T1 weighted post-contrast MRI showing enhancing, heterogeneous large pituitary adenoma (A). Coronal T1 weighted post-contrast MRI showing enhancing, heterogeneous large pituitary adenoma, having mass effect on optic chiasm and ventricles (B).

Table 1: Hormonal profile of the patient

\begin{tabular}{lll}
\hline & Results & Reference range \\
\hline Prolactin & $6,705 \mathrm{ng} / \mathrm{ml}$ & $1.8-20 \mathrm{ng} / \mathrm{mL}$ \\
Growth hormone & $0.18 \mathrm{ng} / \mathrm{ml}$ & $1.18-27.0 \mathrm{ng} / \mathrm{ml}$ \\
IGF- I & $141 \mathrm{ng} / \mathrm{ml}$ & $219-614.4 \mathrm{ng} / \mathrm{mL}$ \\
Morning cortisol & $15.3 \mathrm{ug} / \mathrm{dl}$ & $4.3-22.4 \mathrm{pg} / \mathrm{dl}$ \\
\hline T4 & $5 \mathrm{micg} / \mathrm{dl}$ & $5.1-14 \mathrm{micg} / \mathrm{dL}$ \\
TSH & $3.2 \mathrm{mU} / \mathrm{L}$ & $0.5-5 \mathrm{mU} / \mathrm{L}$ \\
\hline
\end{tabular}

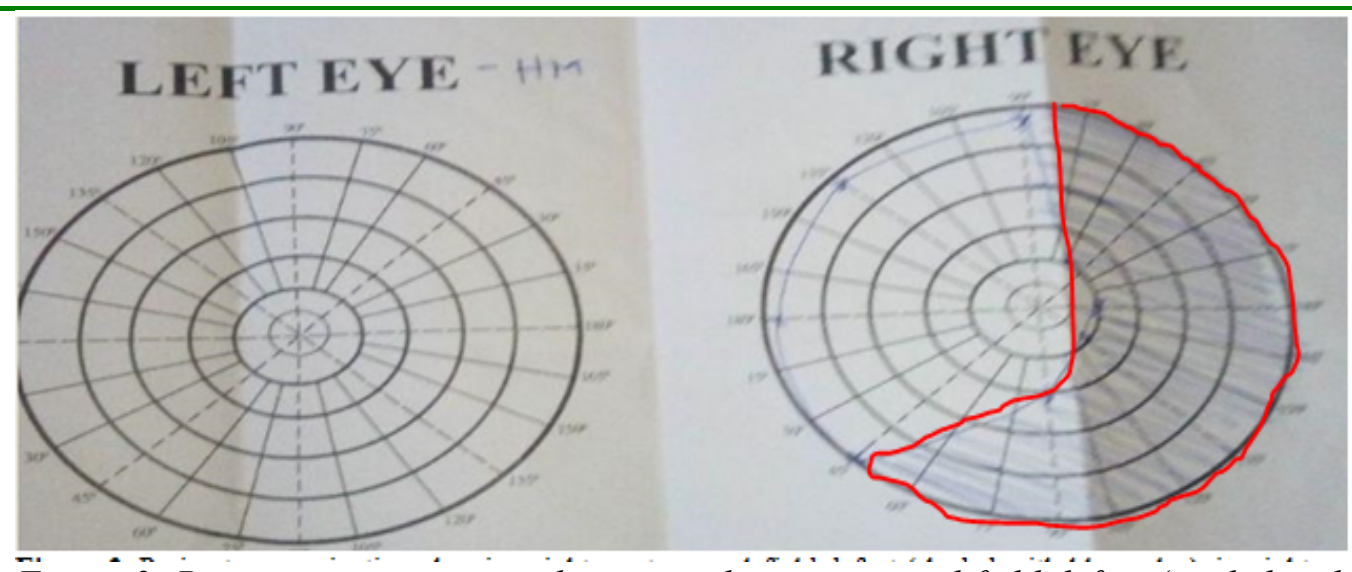

Figure 2: Perimetry examination showing right eye temporal field defect (circled with red), consistent with right side temporal homonymous hemianopia. No field defect was detected on left side because of optic atrophy

DOI: http://dx.doi.org/10.4314/ejhs.v30i2.19 


\section{DISCUSSION}

Pituitary adenomas comprise up to $16 \%$ of all diagnosed primary brain tumors and are the third most common primary tumor. They become more common with age and have a female preponderance in younger patients. Pituitary adenomas may present with symptoms from compression of local structures, including the normal pituitary, optic chiasm, hypothalamus, third ventricle, and endocrinopathy (2). Because the causes of intracranial hypertension are generalized phenomena, papilledema is almost universally bilateral, although it may be asymmetric. If there is underlying optic nerve injury or disease, then the appearance of papilledema may be unilateral, since the damaged nerve does not swell. The classic example is the Foster Kennedy syndrome in which commonly a frontal lobe tumor compresses and destroys the optic nerve on one side before causing increased intracranial pressure. This gives rise to optic atrophy in one eye and disc edema in the other (5).

Our case showed that giant pituitary adenomas can cause mass effect on adjacent optic nerve resulting in optic atrophy. In addition, the giant adenoma may also result in increased intracranial pressure which ultimately results in papilledema of the healthy optic disc resulting in clinical phenomenon called Foster Kennedy syndrome. This case highlighted that pituitary adenoma may present with the full picture of Foster Kennedy syndrome. Therefore, we recommend considering pituitary adenoma as a possible differential diagnosis for patients who present with clinical features of Foster Kennedy syndrome. Early detection and management of the underlying pathology may result in reversal of visual disturbance observed in such patients. Finally, this case also strengthens the common understanding of prolactinoma being highly responsive to medical treatment alone.

\section{ACKNOWLEDGMENT}

We like to acknowledge the Department of Neurology, College of Health Sciences, Addis Ababa University and the patient for their collaboration.

\section{REFERENCES}

1. Laws ER, Sheehan JP. Sellar and Parasellar Tumors: Diagnosis, Treatments, and Outcomes. New York: Thieme, 2012.

2. DeLellis RA, Lloyd RV, Heitz PU, World Health Organization Classification of Tumours: Pathology and Genetics of Tumours of Endocrine Organs. Lyon: IARC Press, 2004.

3. Gutenberg A, Larsen J, Lupi I et-al. A radiologic score to distinguish autoimmune hypophysitis from non-secreting pituitary adenoma preoperatively. AJNR Am $J$ Neuroradiol. 2009;30 (9): 1766-72. doi:10.3174/ajnr.A1714.

4. Simon R., John E., Richard H., Pituitary adenoma presenting as the Foster-Kennedy syndrome. British Journal of Ophthalmology, 1992, 76, 117-119.

5. Kennedy F. Retro bulbar neuritis as an exact diagnostic sign of certain tumours and abscesses in the frontal lobe. AmJ7Med Sci, 1911; 142: 355-68. 